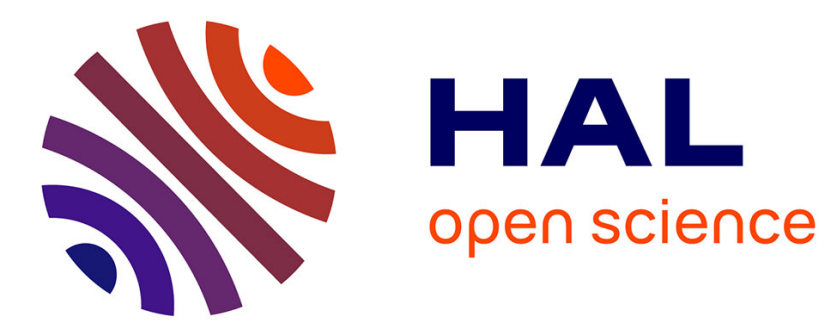

\title{
Insights of the kolliphor/water system for the design of mesostructured silica materials
}

\author{
Claudia Violeta Cervantes-Martinez, Mélanie Emo, Bénédicte Lebeau, \\ Maria-José García-Celma, Marie-José Stebe, Jean-Luc Blin
}

\section{To cite this version:}

Claudia Violeta Cervantes-Martinez, Mélanie Emo, Bénédicte Lebeau, Maria-José GarcíaCelma, Marie-José Stebe, et al.. Insights of the kolliphor/water system for the design of mesostructured silica materials. Microporous and Mesoporous Materials, 2019, 285, pp.231-240. 10.1016/j.micromeso.2019.05.019 . hal-02381507

\section{HAL Id: hal-02381507 \\ https://hal.science/hal-02381507}

Submitted on 22 Oct 2021

HAL is a multi-disciplinary open access archive for the deposit and dissemination of scientific research documents, whether they are published or not. The documents may come from teaching and research institutions in France or abroad, or from public or private research centers.
L'archive ouverte pluridisciplinaire HAL, est destinée au dépôt et à la diffusion de documents scientifiques de niveau recherche, publiés ou non, émanant des établissements d'enseignement et de recherche français ou étrangers, des laboratoires publics ou privés.

\section{(ㅇ)(1) $\$$}

Distributed under a Creative Commons Attribution - NonCommerciall 4.0 International 


\section{Insights of The Kolliphor/Water System For The Design of Mesostructured}

\section{Silica Materials}

Claudia Violeta Cervantes-Martinez ${ }^{1}$, Mélanie Emo ${ }^{1}$, Bénédicte Lebeau ${ }^{2,3}$, Maria-José

García-Celma ${ }^{4,5}$, Marie-José Stébé ${ }^{1}$, Jean-Luc Blin ${ }^{1 *}$

1 : Institut Jean Barriol, UMR CNRS 7053 L2CM, Université de Lorraine, Faculté des Sciences et technologies, BP 70239, 54506 Vandoeuvre lès Nancy cedex, FRANCE

2 : Université de Haute Alsace (UHA), CNRS, IS2M UMR 7361, F-68100 Mulhouse, France

${ }^{3}$ : Université de Strasbourg, 67000 Strasbourg, France

${ }^{4}$ : Department of Pharmacy and Pharmaceutical Technology and Institute of Nanoscience and Nanotechnology (IN ${ }^{2} \mathrm{UB}$ ), University of Barcelona, Av/ Joan XXIII s/n, 08028 Barcelona, Spain

5 : CIBER of Bioengineering, Biomaterials and Nanomedicine (CIBER-BBN), Barcelona, Spain

*Corresponding authors

Pr. Jean-Luc Blin

Université de Lorraine

UMR CNRS 7053 L2CM

Faculté des Sciences et Technologies

BP 70239

F-54506 Vandoeuvre-lès-Nancy cedex, France

Tel. +33 383684370

E-mail: Jean-Luc.Blin@univ-lorraine.fr 


\section{ABSTRACT}

Herein, mesostructured silica materials have been prepared through the Cooperative Templating Mechanism (CTM) using kolliphor EL (KEL) as biocompatible surfactant.

First, the behavior of KEL in water has been studied and the phase diagram has been determined. KEL forms micelles $\left(\mathrm{L}_{1}\right)$ in water and in higher concentrations a liquid crystal domain appears, which is constituted of a cubic phase (Pm3n) and a direct hexagonal phase. Small Angle X-ray Scattering (SAXS) experiments were performed to study the structure of the Organized Molecular Systems. We show that KEL leads to spherical micelles in water, which have a radius comprised between 6.2 and $6.5 \mathrm{~nm}$, depending on the surfactant concentration.

Then, mesoporous materials were synthesized and characterized by SAXS measurements and nitrogen adsorption-desorption analysis. The structure of the recovered material is affected by the surfactant/silica molar ratio. Indeed, the mesopore ordering is detected only for ratios in the range between 0.017 and 0.031 . As long as ordered mesostructures are obtained, the mesopores diameters are in accordance with the dimension of the hydrophobic size of the micelles.

Keywords : Biocompatible surfactant, Phase diagram; Micelles structure; Synthesis parameters Mesostructured silica 


\section{Introduction}

Mesoporous materials are materials with pore size between 2 and $50 \mathrm{~nm}$ according to the IUPAC nomenclature. Their main characteristic is their high surface area and their big pore volume [1,2]. They also offer a relatively large pore size compared with the zeolites, and allow the diffusion of larger molecules. Thanks to their properties they have several potential applications in many fields, such as adsorbents, catalysts, host matrixes for electronic and photonic devices and sensors [3-5]. To develop these applications, much efforts have been devoted to favor their ecodesign [6,7] and to simplify the synthesis procedures [8].

Regarding their mechanisms of formation there exist two main mechanisms, the Cooperative Templating Mechanism (CTM) [6-12] and the Liquid Crystal Templating (LCT) [13-15]. Both mechanisms require the presence of an Organized Molecular System. The LCT pathway consists on the transcription of a liquid crystal already formed, whereas the CTM route produces a material with an ordering resulting from the interactions between the silica precursor and a micellar phase. Indeed, in the initial step, the interactions between small silica oligomers and surfactants drive in a cooperative way the formation of hybrid organicinorganic micelles or aggregates. Then, the condensation of the inorganic precursor at the external surface of the micelles occurs. The ordered mesophase is obtained after intermicellar condensation. Finally, the hydrothermal treatment at higher temperature completes the assembly of micelles and the polymerization of the silica source. The ordered mesoporous material is recovered after surfactant removal. Numerous hydrogenated or fluorinated surfactant-based systems have been investigated as structure directing agents [1,2,11,16-20]. By this way, different kinds of materials called MCM (Mobil Crystalline Materials) [1,2], SBA (Santa Barbara) [9], MSU (Michigan State University) [10] have been obtained.

Recently more interest of mesoporous materials has been focused on their use in drug delivery. In that case, the organized porosity has been used to achieve a sustained, controlled 
or pulsed release in drug delivery [21,22]. Their large surface areas together with their large pore volumes have been used to improve the solubility of poorly soluble drugs and their low density allows them to flat into the gastrointestinal tract and prolong the gastric retention of oral drugs. The drug loading into the mesostructured silica is usually performed by physisorption through interactions with the silanol groups. However, the hydrophobic features of most of the drugs limit their diffusion inside the mesopores, resulting in a low drug loading and in a heterogeneous distribution. Much effort has been devoted to overcome this drawback, silica materials can be functionalized with hydrophobic groups. By this way the interactions between the mesostructured material and the drug are enhanced as a consequence a higher loading is achieved and the kinetic of release is facilitated and better controlled.

Another way to improve the drug loading and to control the drug release consists in designing mesostructured hybrid carriers. In that case the surfactant is not eliminated, playing a dual role. First, it allows the solubilization of the drug, then, it acts as a template for the formation of the silica network. For this kind of application, even if silica, especially the one prepared by sol-gel chemistry [23], is known to be safe, not only for the environment, but also for the human body within a certain dose [24], one peculiar attention should be paid to the components used to prepare the silica mesostructure. In literature some studies concern preparation of such hybrid carriers, mainly mesoporous nanoparticles, from cetyltrimethylammonium bromide (CTABr) surfactant [25-27], but applications are rather limited because of the high toxicity of CTABr. The use of biocompatible and nontoxic surfactant is barely reported. For example, Botella et al. [28] have developed the synthesis of ordered mesoporous silica from alkyl maltoside surfactants as organic structure agents under biomimetic conditions. The authors have also demonstrated that the hybrid materials are effective carriers for the delivery of ibuprofen. The drug has been encapsulated in the hydrophobic core of the micelles template prior to the mineralization with TMOS as the silica 
source. The design of mesostructured silica from biocompatible and nontoxic components is thus still worth to be investigated. In this paper, we have investigated the ability of kolliphor EL, named KEL, to generate ordered mesoporous materials through the Cooperative Templating Mechanism (CTM). The main component of kolliphor EL is glycerol polyethylene glycol ricinoleate. The fatty acid forms the hydrophobic part of the product. The hydrophilic side consist of ethoxylated groups. KEL is widely used as a non-ionic oil-in-water emulsifier and/or solubilizer. This established product demonstrates very good compatibility with other ingredients, and can be used with fat-soluble vitamins and essential oils, or as a purified solubilizer in paclitaxel formulations. To the best of our knowledge, KEL has not been yet considered for the preparation of mesoporous silica. When the CTM pathway is used to synthesize these materials, the characteristics of the recovered materials, such as the structure and the pore diameter, are strongly related to the phase behavior of the structure directing agent in the synthesis solvent. Therefore, in a first part of the present work, we have determined the phase diagram of KEL in water and we have investigated the micellar structure by SAXS. Since the synthesis conditions, such as the quantity of silica source or the surfactant concentration also play an important role in getting a well-defined architecture [2932], we have studied their influence on the properties of the mesostructure in order to optimize the synthesis parameters.

\section{Materials and methods}

Kolliphor EL (Scheme 1), which is a surfactant synthetized from the reaction of castor oil and ethylene oxide in a molar ratio 1:35 (BASF Corporation, technical literature), was purchased from Sigma Aldrich and used as received, without any further purification. Deionized water was obtained using a Milli-Q water purification system. Tetramethoxysilane (TMOS), used as the silica source, was purchased from Sigma Aldrich. 


\subsection{Phase diagram determination:}

Samples were prepared, by weighting the needed amounts of surfactant and water in hermetically sealed glass tubes. The homogenization of the samples was done by mixing with a vortex stirrer. To improve the homogeneity of the samples, they were also centrifuged several times.

The phase diagram was established by preparing samples over the whole range of surfactant/water concentrations, and placing them in a water bath at the desired temperature until reaching equilibrium (1 week). Visual observations coupled with polarized light optical microscopy (Olympus BX 50) were used to identify the different phases and to determine the mono-, bi- or multiphasic domains. Additional Small Angle X-ray Scattering measurements were performed to establish precisely the phase boundaries and to confirm the nature of the different phases.

\subsection{Silica materials preparation}

To synthesize the mesostructured materials, micellar solutions were first prepared with aqueous solutions at $\mathrm{pH}=7.0$ and at $25^{\circ} \mathrm{C}$. Six concentrations of surfactant in water were investigated, $2.5,5,10,20,30$ and 40 wt. \%. Then, TMOS was added dropwise to the

solutions and the mixtures were stirred at $300 \mathrm{rpm}$ for $1 \mathrm{~h}$. The surfactant/silica molar ratio (R') was varied from 0.017 to 0.066 .

In all cases after preparation the obtained mixtures were placed into sealed Teflon autoclaves at $40^{\circ} \mathrm{C}$ for $24 \mathrm{~h}$, then at $100^{\circ} \mathrm{C}$ for $24 \mathrm{~h}$. After the hydrothermal treatment, the materials were transferred into cellulose extraction cartridges to remove the template by Soxhlet ethanol extraction for $48 \mathrm{~h}$. After drying at room temperature during $24 \mathrm{~h}$, samples were thermally treated under synthetic air as follow. A first temperature increase was applied at $2{ }^{\circ} \mathrm{C} / \mathrm{min}$ 
until $150{ }^{\circ} \mathrm{C}$ with a $1 \mathrm{~h}$ plateau, followed by a second temperature ramp at $2{ }^{\circ} \mathrm{C} / \mathrm{min}$ to reach $350{ }^{\circ} \mathrm{C}$. Temperature was held for $1 \mathrm{~h}$, then, a final temperature ramp at $2{ }^{\circ} \mathrm{C} / \mathrm{min}$ was imposed to reach $550{ }^{\circ} \mathrm{C}$ with a $1 \mathrm{~h}$ plateau. The cooling process was uncontrolled and directed by the oven inertia.

\subsection{Characterization}

Small angle X-Ray scattering (SAXS) measurements were carried out on a "SAXSess mc"" instrument (Anton Paar), using line-collimation system. This instrument is attached to a ID 3003 laboratory X-Ray generator (General Electric) equipped with a sealed X-Ray tube (PANalytical, $\lambda \mathrm{Cu}, \mathrm{K} \alpha=0.1542 \mathrm{~nm}$ ) operating at $40 \mathrm{kV}$ and $50 \mathrm{~mA}$. Each sample was introduced in a "Special Glass" capillary, with a diameter equal to $1.5 \mathrm{~mm}$ and $2.0 \mathrm{~mm}$ for micellar solutions and liquid crystals, respectively, or between two sheets of Kapton ${ }^{\circledR}$ for materials, then placed inside an evacuated sample chamber and exposed to X-Ray beam. Scattering of X-Ray beam was recorded on a CCD detector (Princeton Instruments, $2084 \mathrm{x}$ 2084 pixels array with $24 \times 24 \mu \mathrm{m}^{2}$ pixel size, sample-detector distance $=309 \mathrm{~mm}$ ). Using SAXSQuant software (Anton Paar), the two-dimensional image was integrated into onedimensional scattering intensities $\mathrm{I}(\mathrm{q})$ as a function of the magnitude of the scattering vector $\mathrm{q}$ $=(4 \pi / \lambda) \sin (\theta)$, where $2 \theta$ is the total scattering angle. Thanks to a translucent beamstop allowing the measurement of an attenuated primary beam at $\mathrm{q}=0$, all measured intensities can be calibrated by normalizing the attenuated primary intensity. All data were then corrected for the background scattering from the cell and for slit-smearing effects by a desmearing procedure from SAXSQuant software, using Lake method. For micellar solutions, after correction, obtained intensities are scaled into absolute units using water as a reference material. Nitrogen sorption isotherms were determined on a Micromeritics TRISTAR 3000 equipment at $-196{ }^{\circ} \mathrm{C}$ over a wide relative pressure range from 0.01 to 0.995 . The pore 
diameter and the pore size distribution were determined by applying the BJH (Barret, Joyner, Halenda) method [33] to the adsorption branch of the isotherm.

Transmission electron microscopy (TEM) images were recorded on a JEOL ARM200-CFEG microscope operating at $200 \mathrm{KV}$. For TEM observation, samples were previously dispersed in chloroform with ultrasounds and few drops of the suspension was spread on Au grid covered by Formvar/amorphous carbon film.

\section{Results and discussion}

\subsection{The Kolliphor EL/water system}

The behavior of the surfactant in water was investigated and the binary phase diagram is represented on Figure 1.

For concentrations below 45 wt. \% of surfactant, micellar solutions stable with temperature are obtained. For higher concentrations of kolliphor EL, liquid crystals phase domain appears. From 46 wt. $\%$ to 58 wt. $\%$ of surfactant, a very stiff and isotropic phase which melts at $30^{\circ} \mathrm{C}$ is observed ; it can be attributed to a cubic phase. The identification of the space group of this cubic phase was determined by SAXS. The relative positions of the reflection lines are $1: \sqrt{\frac{3}{2}}$ : $\sqrt{2}: \sqrt{\frac{5}{2}}: \sqrt{3}: \sqrt{\frac{29}{4}}$, which can be assigned to the $P m 3 n$ direct micellar cubic phase. From 58 wt. $\%$ to 68 wt. $\%$ of surfactant and up to almost $50{ }^{\circ} \mathrm{C}$, an hexagonal phase is obtained. Indeed, the pictures observed by polarized light optical microscopy show a characteristic texture and the relative positions of the reflection lines on the SAXS patterns are $1: \sqrt{3}: 2$.

The structural parameters of these liquid crystals phases were determined at several temperatures $\left(10,20,25\right.$ and $\left.30^{\circ} \mathrm{C}\right)$ by using SAXS. For the cubic phase, the ratio water / Kolliphor (R) equal to 1 was investigated and for the hexagonal phase the studied ratios were 0.67 and 0.54 . The structural parameters were determined in accordance with the equations 
reported in the literature [34]. The lattice parameters $a$ were obtained from the following equations :

$$
a=\frac{4 \pi}{q_{0} \sqrt{3}} \text { (for the hexagonal phase) } \quad \frac{q_{h k l}}{2 \pi}=\frac{1}{a} \cdot \sqrt{h^{2}+k^{2}+l^{2}} \text { (for the cubic phase) }
$$

with $\mathrm{q}_{0}$, the position of the first reflection and $\mathrm{q}_{\mathrm{hkl}}$ is the position of the peak for the reflection line $(h k l)$.

For the hexagonal phase, the hydrophobic radius $\mathrm{R}_{\mathrm{H}}$ is related to the distance $d$ associated to the first reflection by the following equation [34]:

$$
\frac{V_{B}}{V_{S}+\propto V_{W}}=\frac{\sqrt{3} \pi R_{H}^{2}}{2 d^{2}}
$$

where $\alpha$ stands for the number of molecules of water per molecule of surfactant, $V_{B}, V_{S}, V_{W}$ respectively stand for the molar volumes of the hydrophobic part of the surfactant, the surfactant and water $\left(\mathrm{V}_{\mathrm{W}}=18 \mathrm{~cm}^{3} / \mathrm{mol}, \mathrm{V}_{\mathrm{B}}=834 \mathrm{~cm}^{3} / \mathrm{mol}\right.$ and $\left.\mathrm{V}_{\mathrm{S}}=2354 \mathrm{~cm}^{3} / \mathrm{mol}\right)$

Then, the cross sectional area $S$ can be deduced as :

$$
S=\frac{2 V_{B}}{N_{A} R_{H}}
$$

where $\mathrm{N}_{\mathrm{A}}$ is the Avogadro's number.

For the cubic phase, the hydrophobic radius $\mathrm{R}_{\mathrm{H}}$ is related to the lattice parameter $a$ by the following equation [34] :

$$
\frac{V_{B}}{V_{S}+\propto V_{W}}=\frac{4 v \pi R_{H}^{3}}{3 a^{3}}
$$

with $v$ the number of micelles per cubic lattice ( $v=8$ for the Pm3n cubic phase).

Then, the cross sectional area $S$ can be deduced as :

$$
S=\frac{3 V_{B}}{N_{A} R_{H}}
$$

The results are given in Table 1 . For the hexagonal phase, the lattice parameter $a$ slightly increases with the content of water from 10.4 to $10.7 \mathrm{~nm}$, while the hydrophobic radius and the cross sectional area remain constant, equal to $2.6 \mathrm{~nm}$ and $1.1 \mathrm{~nm}^{2}$, respectively. The value of $R_{H}$ is higher for the cubic phase $(3.5 \mathrm{~nm})$, while the cross sectional area is in the same 
range $\left(1.2 \mathrm{~nm}^{2}\right)$. No significant change of the structural parameters in function of the temperature was observed. Given that, from the length of the bonds, the extended alkyl chains have a dimension of about $2.5 \mathrm{~nm}$ and looking at the determined values of the hydrophobic radius for the hexagonal phase, we can deduce that the alkyl chains are completely extended in this phase. For the cubic phase, the hydrophobic radius is bigger than the estimated value. This result can be due to the deviation from the perfect spherical micelles to slightly rods in the Pm3n cubic phase, as suggested by Fontell et al. [35], or to disks as proposed in the Charvolin and Sadoc model [36].

The structure of the micelles of Kolliphor in water were determined by SAXS with the samples at 2.5, 5 and $10 \mathrm{wt} . \%$ of surfactant. The SAXS spectra are given on Figure 2a in absolute units.

For all the studied concentrations, the spectra present the same profile. All the curves are overlapped for $q>0.45 \mathrm{~nm}^{-1}$ and they exhibit a maximum at $0.78 \mathrm{~nm}^{-1}$. For low $q$ values $(q<$ $\left.0.45 \mathrm{~nm}^{-1}\right)$, the intensity decreases with the concentration. This feature is characteristic of the existence of interparticle interactions.

To determine the micellar structure, the data were analyzed by using the Generalized Indirect Fourier Transform (GIFT) method [37,38], taking into consideration the interparticle interactions (Figure 2b). The obtained pair-distance distribution functions (PDDFs) were represented on Figure 2c. The curves exhibit a pronounced dip, which even goes to negative values for the concentrated solution (10 wt.\%), indicating that the micelles can be considered as inhomogeneous and so called "core-shell" type particles. All the curves present also a belllike shape, characteristic of spherical micelles, with a maximum dimension of about $12.5-13$ $\mathrm{nm}$, regardless of the surfactant concentration. These results are in good agreement with the hydrodynamic diameter determined at $25^{\circ} \mathrm{C}$ by Dynamic Light Scattering (DLS) measurements (14 nm with diluted micellar solutions (<2wt.\% of surfactant)). Additionally, 
the excess-electron density profiles have been determined by the deconvolution of the pairdistance distribution functions (PDDFs) (Figure 2d). The profiles confirm the core-shell type particles for the three micellar solutions. Indeed, the negative density difference corresponds to the hydrophobic part $\left(\rho_{\text {phobic }}=310 \mathrm{e} / \mathrm{nm}^{3}\right)$, whereas the positive density difference can be attributed to the hydrophilic shell $\left(\rho_{\text {philic }}=369 \mathrm{e} / \mathrm{nm}^{3}\right)$. The hydrophobic radius corresponds to the $r$-value when the sign of $\Delta \rho(\mathrm{r})$ changes. It can be estimated at 3.1 and $3.3 \mathrm{~nm}$ for 2.5 and 5-10 wt. \% surfactant concentration, respectively. Then, the micelles radii can be evaluated at 6.2 and $6.5 \mathrm{~nm}$ for 2.5 and 5-10 wt. \% surfactant concentration, respectively. These values are in accordance with the maximum dimension found on the PDDFs. Looking at the excess electron density profile (Figure 2d), the hydrophobic moieties, corresponding to the lowest values of $\Delta \rho(\mathrm{r})$, have a dimension of about 1.9-2.0 $\mathrm{nm}$ since the dimension of the hydrophobic chains is estimated at $2.5 \mathrm{~nm}$. We can thus deduce that the alkyl chains are very slightly folded. For the hydrophilic chains, considering that one EO group has a dimension of 0.35 $\mathrm{nm}$, their total dimension can be evaluated at $4.5 \mathrm{~nm}$. From Figure $2 \mathrm{~d}$, the hydrophilic part has a length of $4-4.5 \mathrm{~nm}$. Thus, these chains have a rather extended conformation.

\subsection{Mesostructured silica materials from Kolliphor micelles}

When the cooperative mechanism is used to prepare the mesostructured silica, the surfactant has to form micelles in solution, but this is not a sufficient condition. Indeed, the other partner, the silica precursor, also plays a crucial role in the formation of the materials $[30,31,39]$. In particular, the surfactant/silica molar ratio is an important parameter that should be optimized. For two kolliphor concentrations belonging to the micellar domain (2.5 and 10 wt.\%), the kolliphor/TMOS molar ratio (R') has been varied from 0.017 to 0.066 . By this way, from the surfactant point of view, the conditions are gathered for the CTM to occur. The observed variations will thus be due to the effect of the inorganic precursor. Whatever the 
kolliphor concentration, mesostructured silica materials are recovered until a kolliphor/TMOS ratio of 0.031 (Fig. 3). If the value of $R^{\prime}$ is increased the main peak becomes less intense and no secondary reflections are detected any longer. This means that the mesopores arrangement evolves towards a wormhole-like structure. In that case, the quantity of the added TMOS is not enough to cover all the micelles and the interactions between micelles and hydrolyzed precursor are disturbed. As a consequence, the intermicellar condensation leads to a less ordered hybrid mesophase and wormhole-like mesostructures are obtained.

Concerning the nitrogen adsorption-isotherm, regardless the synthesis conditions, all the materials present a type IV isotherm (Fig. 4), characteristic of mesoporous materials. For R' ratios in the range $0.017-0.031$, the mesopore size distribution is quite narrow and the pore diameter remains almost constant for a given kolliphor concentration (insert of Fig 4). An increase of the mesopore size is noted when the KEL concentration is varied from 2.5 to 10 wt.\%, for example, for $\mathrm{R}^{\prime}=0.017$ the pore diameter increases from 4.7 to $5.7 \mathrm{~nm}$. We can also see that the nitrogen adsorption-desorption isotherm of materials synthesized with a kolliphor/TMOS ratio in this range of values, increases at high relative pressure instead of reaching a plateau as usually observed for type IV isotherms. This behavior has already been reported in literature $[31,40]$ and can be related to the $\mathrm{pH}$ conditions which favor the appearance of an interparticular porosity, which is responsible of the ascent of the adsorbed volume at high $\mathrm{p} / \mathrm{p}_{0}$ values. For $\mathrm{R}^{\prime}$ beyond 0.031 , the disorganization of the mesopores network is accompanied by a decrease of the pore diameter (insert of Fig. 4A) or by the appearance of a broad second component in the mesopore size distribution (insert of Fig. 4B), consequence of the hybrid mesophase reorganization due to the insufficiency of the amount of the inorganic precursor. According to TEM observations at high magnification (Fig. 5) materials with KEL concentration of $2.5 \%$ are mesoporous. Mesopores appear larger and more regular in size for $\mathrm{R}^{\prime}=0.024$, that is consistent with SAXS and nitrogen 
adsorption/desorption data. It can be clearly observed that pore size increases from $\mathrm{R}^{\prime}=0.017$ to 0.024 and then decreases from $\mathrm{R}^{\prime}=0.024$ to 0.044 . It is interesting to note that particles at $\mathrm{R}^{\prime}=0,024$ are smaller and regular in size compared to the others.

From the above results, obtained for a low and high surfactant concentration, it appears that to recover a mesostructured silica with a well-defined pore size distribution the $\mathrm{R}$ 'value should be in the range between 0.017 and 0.031 . Thus, for the next studies, the kolliphor/TMOS ratio has been fixed to 0.024. Since it also appears that the pore size varies as a function of the kolliphor concentration, the surfactant amount has been varied from 2.5 to $40 \mathrm{wt} . \%$ to explore the overall micellar domain. The SAXS patterns depicted on Figure 6A show that mesostructured silica materials are recovered until $20 \mathrm{wt} \% \%$ of kolliphor in water (Fig. 6Aa-d). Increasing the concentration of the micellar solutions from 2.5 to $20 \mathrm{wt} . \%$, the first peak $\mathrm{d}_{100}$ is shifted from 7.3 to $10 \mathrm{~nm}$, the cell parameter $\mathrm{a}_{0}$ thus varies from 8.4 to $11.5 \mathrm{~nm}\left(\mathrm{a}_{0}=\right.$ $\left.2 d_{100} / \sqrt{3}\right)$. Since the cell parameter is the sum of the mesopore diameter $(\varnothing)$ and the silica wall thickness (e) this suggests that either $\varnothing$ or e or both increase as a function of the kolliphor concentration. In this range of KEL concentration, the mesostructured silica presents a type IV isotherm (Fig. 6Ba-d) characteristic of mesoporous materials, according to the IUPAC classification [41]. The relative pressure at which the capillary condensation occurs is progressively shifted to higher $\mathrm{p} / \mathrm{p}_{0}$ values when the surfactant concentration used to prepare the materials is increased. Since this value is related to the mesopore diameter according to the Kelvin equation this means that bigger mesopores are formed. This is confirmed by the pore size distribution, whose maximum is shifted from 4.5 to $7.1 \mathrm{~nm}$ as a function of the kolliphor concentration. By contrast it can be seen from Table 2 that the mesopore wall thickness remains almost constant to $4.0 \mathrm{~nm}$. It is also interesting to note that the mesopore diameter is in good accordance with the hydrophobic core size of the micelles determined by SAXS. This observation confirms the templating effect of the KEL micelles. 
The specific surface area and the pore volume slowly increase from respectively 702 to around $900 \mathrm{~m}^{2} / \mathrm{g}$ and from 0.7 to $1.5 \mathrm{~cm}^{3} \cdot \mathrm{g}^{-1}$, when the KEL concentration varies from 2.5 to 20 wt.\% (Table 2).

The SAXS spectrum of the material synthesized with $30 \mathrm{wt} . \%$ of kolliphor is characteristic of a wormhole-like structure since it exhibits only a broad peak at $12.7 \mathrm{~nm}$ (Fig.5Ae). If the KEL concentration is raised to $40 \mathrm{wt} . \%$ no peak is detected any longer (Fig. 5Af), meaning that the channel arrangement is completely random. The shape of the isotherm of the samples prepared with a KEL concentration higher than 20 wt.\% is modified and it becomes intermediate between type IV and type II (Fig. 5Be,f). Meanwhile the pore size is broader, its maximum is shifted towards higher mesopore diameter and the $\mathrm{dV} / \mathrm{dD}$ values decrease. Meantime the specific surface area drops to around $460 \mathrm{~m}^{2} / \mathrm{g}$, reflecting disorganization of the channel array even if all the conditions are gathered to get an ordered mesostructured silica material. TEM observations confirm the presence of regular mesopores for all samples with $\mathrm{R}^{\prime}=0.024$ when KEL concentration increased from 2.5 to 30 wt.\% (Fig. 7). On the TEM images at high magnification (Fig. $7 \mathrm{~b}, \mathrm{~d}, \mathrm{f}, \mathrm{h}, \mathrm{j}$ ) the gradual loss of pore ordering is clearly observed when KEL concentration increased from 10 to $30 \mathrm{wt} . \%$. The origin of the loss of the mesopore ordering with the increase of the surfactant concentration can be due to a change of the micelles shape for example from spherical to rods, which disturbs the Cooperative Templating Mechanism. Indeed, when micelles are closed together, due to the limitations on the conformation of oxyethylene groups arising from steric hindrance, repulsive forces occur. This leads to a micelle shape transition like sphere-to-rod [42]. We can also assume that with the increase of the concentration of the micellar solution more and more micelles are formed and the interactions between micelles predominate in the detriment of the ones with the hydrolyzed precursor. Finally, we cannot exclude a shift of the domain of the phase diagram because of the release of the methanol produced during the hydrolysis of the TMOS. Indeed, 
it is well known that the presence of additives such as salt or alcohol strongly modify the surfactant behavior in water $[43,44]$ and as a consequence affect the formation of the mesostructured silica materials $[45,46]$.

\section{Conclusions}

Mesoporous materials have been prepared using an aqueous solution of a biocompatible surfactant, the kolliphor EL. In order to determine the phase sequence as a function of the temperature, the phase behavior of KEL in aqueous solution was first investigated. We have delimited the different phase domains and determined the structure of the micelles as well as the structural parameters of the liquid crystals.

Determination of the micellar structure by SAXS provides information about the conformation of the hydrophilic and hydrophobic chains in $\mathrm{L}_{1}$. The alkyl chains are slightly folded whereas the hydrophilic chains are rather extended. The micelles are found to be spherical and their radius has been evaluated between 6.2 and $6.5 \mathrm{~nm}$, depending on the kolliphor concentration. In the liquid crystals phases $\mathrm{H}_{1}$ and $\mathrm{I}_{1}$, the hydrophobic chains adopt an extended conformation.

Micellar solutions of kolliphor EL were used as template to prepare the mesoporous materials through the Cooperative Templating Mechanism. The influence of the synthesis conditions on the properties of the mesopore ordering has been investigated. As long as the surfactant concentration is lower than $30 \mathrm{wt} \%$ ordered mesoporous silica can be obtained. These materials exhibit a high specific surface area and a narrow pore size distribution, whose maximum varies from 4.5 to $7.1 \mathrm{~nm}$. These values of the mesopores diameters are in accordance with the ones of the size of the hydrophobic core of the micelles determined by SAXS. If the kolliphor concentration is increased, disordered mesoporous silica with broad mesopore size distributions are recovered. 
Here, we succeed in preparing bare silica from the biocompatible surfactant Kolliphor EL. KEL has been remove to characterize the porosity. Regarding the interest of hybrid materials for drug delivery we can assume that without removing KEL the hybrid mesostructured silica are excellent candidates for this application. This work is under progress.

\section{Acknowledgements :}

Claudia Violeta Cervantes-Martinez thanks the CONACYT for the financial support of her PhD. Loïc Vidal the person in charge of the "Electronic Microscopy" platform of IS2M is acknowledged for TEM images. 


\section{References}

[1] C. T. Kresge, W. J. Roth, The discovery of mesoporous molecular sieves from the twenty year perspective, Chem. Soc. Rev. 42 (2013) 3663-3670.

[2] C.T. Kresge, M.E. Leonowicz, W.J. Roth, J.C. Vartuli, J.S. Beck, Ordered mesoporous molecular sieves synthesized by a liquid-crystal template mechanism, Nature 359 (1992) 710-712.

[3] L. F. F. P. G. Braganca, M. Ojeda, J.L.G. Fierro, M.I. Pais da Silva, Bimetallic Co-Fe nanocrystals deposited on SBA-15 and HMS mesoporous silicas as catalysts for Fischer-Tropsch synthesis, Appl. Catal. A-Gen. 423-424 (2012) 146-153.

[4] P. Perego, R. Millini, Porous materials in catalysis: challenges for mesoporous materials, Chem. Soc. Rev. 42 (2013) 3956-3976.

[5] S.Y. Park, M. Barton, P. Pendleton, Mesoporous silica as a natural antimicrobial carrier, Colloids and Surfaces A: Physicochem. Eng. Aspects 385 (2011) 256-261.

[6] N. Baccile, F. Babonneau, B. Thomas, T. Coradin, Introducing ecodesign in silica solgel materials, J. Mater. Chem. 19 (2009) 8537-8559.

[7] C. Gérardin, J. Reboul, M. Bonne, B. Lebeau, Ecodesign of ordered mesoporous silica materials, Chem. Soc. Rev. 42 (2013) 4217-4255.

[8] J. A. Martens, J. Jammaer, S. Bajpe, A. Aerts, Y. Lorgouilloux, C.E.A. Kirschhock, Simple synthesis recipes of porous materials, Microporous and Mesoporous Mater. 140 (2011) 2-8.

[9] D. Zhao, Q. Huo, J. Feng, B.F. Chmelka, G.D. Stucky, Nonionic triblock and star diblock copolymer and oligomeric surfactant syntheses of highly ordered, hydrothermally stable mesoporous silica structures, J. Am. Chem. Soc. 120 (1998) 6024-6036. 
[10] S.A. Bagshaw, E. Prouzet, T.J. Pinnavaia, Templating of mesoporous molecular sieves by nonionic polyethylene oxide surfactants, Science 269 (1995) 1242-1244.

[11] Y. Wan, D. Zhao, On the controllable soft-templating approach to mesoporous silicates, Chem. Rev. 107 (2007) 2821-2860.

[12] J. L. Blin, M. Impéror-Clerc, Mechanism of self-assembly in the synthesis of silica mesoporous materials: in situ studies by X-ray and neutron scattering, Chem. Soc. Rev. 42 (2013) 4071-4082.

[13] G. S. Attard, J.C. Glyde, C.G. Göltner, Liquid-crystalline phases as templates for the synthesis of mesoporous silica, Nature 378 (1995) 366-368.

[14] S.A. El-Safty, Y. Kiyozumi, T. Hanaoka, F. Mizukami, Controlled design of ordered and disordered pore architectures, geometries, and dimensions of HOM-type mesostructured monoliths and their hydrothermal stabilities, J. Phys. Chem. C 112 (2008) 5476-5489.

[15] K. Zimny, J.L. Blin, M.J. Stébé, Ordered mesoporous silica templated by nonionic fluorinated liquid crystals, J. Phys. Chem. C 113 (2009) 11285-11293.

[16] I. Park, T.J. Pinnavaia, Large-pore mesoporous silica with three-dimensional Wormhole framework structures, Microporous and Mesoporous Mater. 118 (2009) 239-244.

[17] K.Z. Hossain, A. Sayari, Synthesis of onion-like mesoporous silica from sodium silicate in the presence of $\alpha, \omega$-diamine surfactant, Microporous and Mesoporous Mater. 114 (2008) 387-394.

[18] J.L. Blin, M.J. Stébé, Effect of fluorocarbon addition on the structure and pore diameter of mesoporous materials prepared with a fluorinated surfactant, Microporous and Mesoporous Mater. 87 (2005) 67-76. 
[19] B. Tan, A. Dozier, H.J. Lehmler, B. Knutson, S.E. Rankin, Elongated silica nanoparticles with a mesh phase mesopore structure by fluorosurfactant templating, Langmuir 20 (2004) 6981-6984.

[20] J. Esquena, C. Rodriguez, C. Solans, H. Kunieda, Formation of mesostructured silica in nonionic fluorinated surfactant systems, Microporous and Mesoporous Mater. 92 (2006) 212-219.

[21] M. Arruebo WIREs, Drug delivery from structured porous inorganic materials, Nanomed. Nanobiotechnol. 4 (2012) 16-30.

[22] M. Moritz, M. Geszke-Moritz, Mesoporous materials as multifunctional tools in biosciences: Principles and applications, Mater. Sci. Eng. C 49 (2015) 114-151.

[23] H. Zhang, D.R. Dunphy, X. Jiang, H. Meng, B. Sun, D. Tarn, M. Xue, X. Wang, S. Lin, Z. Ji, R. Li, F.L. Garcia, J. Yang, M.L. Kirk, T. Xia, J.I. Zink, A. Nel, C.J. Brinker, Processing pathway dependence of amorphous silica nanoparticle toxicity colloidal versus pyrolytic, J. Am. Chem. Soc. 134 (2012) 15790-15804.

[24] Complementary Medicine Evaluation Committee, 16th meeting, (n.d.).

[25] A. Corma, M. Moliner, M. J. Díaz-Cabanas, P. Serna, B. Femenia, J. Primo and H. García, Biomimetic synthesis of microporous and mesoporous materials at room temperature and neutral $\mathrm{pH}$, with application in electronics, controlled release of chemicals, and catalysis, New J. Chem. 32 (2008) 1338-1345.

[26] N. W. Clifford, K. S. Iyer and C. L. Raston, Encapsulation and controlled release of nutraceuticals using mesoporous silica capsules, J. Mater. Chem. 18 (2008) 162-165.

[27] Q. He, J. Shi, F. Chen, M. Zhu and L. Zhang, An anticancer drug delivery system based on surfactant-templated mesoporous silica nanoparticles, Biomaterials, 31 (2010) 3335-3346. 
[28] P. Botella, A. Corma, M. Quesada, Synthesis of ordered mesoporous silica templated with biocompatible surfactants and applications in controlled release of drugs, J. Mater. Chem. 22 (2012) 6394-6401.

[29] P.F. Fulvio, S. Pikus, M. Jaroniec, Tailoring properties of SBA-15 materials by controlling conditions of hydrothermal synthesis, J. Mater. Chem. 15 (2005) 50495053.

[30] T. Benamor, L. Vidal, B. Lebeau, C. Marichal, Influence of synthesis parameters on the physico-chemical characteristics of SBA-15 type ordered mesoporous silica, Microporous and Mesoporous Mater. 153 (2012) 100-114.

[31] A. Léonard, J.L. Blin, P.A. Jacobs, P. Grange, B.L. Su, Chemistry of silica at different concentrations of non-ionic surfactant solutions: effect of $\mathrm{pH}$ of the synthesis gel on the preparation of mesoporous silicas, Microporous and Mesoporous Mater. 63 (2003) $59-73$.

[32] A. Galarneau, M. Nader, F. Guenneau, F. Di Renzo, A. Gedeon, Understanding the stability in water of mesoporous SBA-15 and MCM-41, J. Phys. Chem. C 111 (2007) 8268- 8277.

[33] E.P. Barrett, L.G. Joyner, P.P. Halenda, The determination of pore volume and area distributions in porous substances. I. Computations from nitrogen isotherms, J. Am. Chem. Soc. 73 (1951) 373-380.

[34] M. Alibrahim, M.J. Stébé, G. Dupont, J.C. Ravey, Effect of an Ionic Surfactant on the Phase Behavior of a Nonionic Surfactant-Based System, J. Chim. Phys. Phys. - Chim. Biol. 94 (1997) 1614-1633

[35] K. Fontell, K.K. Fox, E. Hansson, On the structure of the cubic phase $\mathrm{I}_{1}$ in some lipidwater systems, Mol. Cryst. Liq. Cryst. 1 (1985) 9-17. 
[36] J. Charvolin, J.F. Sadoc, Periodic systems of frustated fluid films and micellar cubic structures in liquid crystals, J. Phys. 49 (1988) 521-526.

[37] O. Glatter, O. Kratky, in: Small Angle X-Ray Scattering, Academic Press, (1982) 167196.

[38] G. Fritz, O. Glatter, Structure and interaction in dense colloidal systems: evaluation of scattering data by the generalized indirect Fourier transformation method, J. Phys.: Condens. Matter 18 (2006) S2403-S2419.

[39] F. Michaux, M.J. Stébé, J.L. Blin, Systematic investigation of the synthesis parameters driving the preparation of mesoporous materials using a nonionic fluorinated surfactant Microporous and Mesoporous Mater. 151 (2012) 201-210.

[40] M. J. Stébé, M. Emo, A. Forny-Le Follotec, L. Metlas-Komunjer, I. Pezron, J. L. Blin, Triblock siloxane copolymer surfactant: template for spherical mesoporous silica with a hexagonal pore ordering, Langmuir 29 (2013) 1618-1626.

[41] K. S. W. Sing, D. H. Everett, R. A. W. Haul, L. Moscou, R. A. Pierotti, J. Rouquerol, T. Siemieniewska, Reporting physisorption data for gas/solid systems with special reference to the determination of surface area and porosity (Recommendations 1984) IUPAC, Pure and Appl. Chem. 57 (1985) 603-619.

[42] D.J. Mitchell, G.J.T. Tiddy, L. Waring, T. Bostock, M.P. Mc Donald, Phase behaviour of polyoxyethylene surfactants with water. Mesophase structures and partial miscibility (cloud points), J. Chem. Soc. Faraday Trans. I, 79 (1983) 975-1000.

[43] H. Schott, Effect of inorganic additives on solutions of nonionic surfactants. J. Colloid Interface Sci. 189 (1997) 117-122.

[44] K. Shinoda, In Principles of Solution and Solubility, J.J. Lagowski (Ed.), M. Dekker Inc., New York and Basel, 1978, p. 180. 
[45] J.L. Blin, N. Du, M.J. Stébé, Alcohols solubilization in a nonionic fluorinated surfactant based system: Effect on the mesoporous silica characteristics J. Colloid Interface Sci. 373 (2012) 34-45.

[46] K. Zimny, J.1. Blin, M.J. Stébé, Influence of methanol on the phase behavior of nonionic fluorinated surfactant: Relation to the structure of mesoporous silica materials, J. Colloid Interface Sci. 330 (2009) 456-462. 


\section{Figure caption}

Scheme 1: Chemical formula of the surfactant Kolliphor EL, with $x+y+z=35$

Figure 1: Concentration-temperature phase diagram of the surfactant-water system. $\mathrm{L}_{1}$ and $\mathrm{L}_{2}$ correspond to direct and reverse micellar phases, respectively, $\mathrm{I}_{1}$ corresponds to a direct micellar cubic phase and $\mathrm{H}_{1}$ corresponds to a direct hexagonal phase. S denotes a solid.

Figure 2: (a) SAXS spectra of the samples at 2.5 wt. $\%$ (green $\circ$ ), 5 wt. $\%$ (blue $\Delta$ ) and 10 wt. \% (purple $\square$ ) of Kolliphor at $25{ }^{\circ} \mathrm{C}$ in $\log$-log representation in absolute units and normalized with regard to the surfactant volume fraction ; (b) Experimental (black dotted line) and approximated (GIFT) (solid line) SAXS spectra at 2.5 wt. \% (green), 5wt. \% (blue) and 10 wt. \% (purple) of Kolliphor at $25{ }^{\circ} \mathrm{C}$; (c) Corresponding pair-distance distribution functions (PDDFs) ; (d) Corresponding excess-electron density profiles.

Figure 3: $\quad$ SAXS patterns of the materials synthesized with a surfactant/TMOS molar ratio ( $\mathrm{R}^{\prime}$ ) equal to a : 0.017 ; b: $0.024 ; \mathrm{c}: 0.031 ; \mathrm{d}: 0.049$; e : 0.051 and $\mathrm{f}$ : 0.066. The micellar concentration is equal to $2.5(\mathrm{~A})$ and $10 \mathrm{wt} . \%(\mathrm{~B})$.

Figure 4: Nitrogen adsorption-desorption isotherms with the corresponding pore size distribution (insert) of the materials synthesized with a surfactant/TMOS molar ratio (R') equal to a : 0.017 ; b: $0.024 ; \mathrm{c}: 0.031 ; \mathrm{d}: 0.049 ; \mathrm{e}: 0.051$ and f : 0.066 . The micellar concentration is equal to $2.5(\mathrm{~A})$ and $10 \mathrm{wt} . \%(\mathrm{~B})$.

Figure 5: $\quad$ TEM images of the materials synthesized with a surfactant/TMOS molar ratio (R') equal to a,b : 0.017; c,d : 0.024; e,f : 0.031; g,h : 0.049. The micellar concentration is equal to $2.5 \mathrm{wt} . \%$.

Figure 6: SAXS patterns (A) and Nitrogen adsorption-desorption isotherms (B) with the corresponding pore size distribution (insert) of the samples synthesized 
with a KEL concentration (wt.\%) of a :2.5, b : 5, c : 10, d : 20, e : 30 and $\mathrm{f}$ : 40. The KEL/TMOS molar ratio is fixed to 0.024 .

Figure 7: TEM images of the samples synthesized with a KEL concentration (wt.\%) of a,b : 2.5, c,d : 5, e,f : 10, g,h : 20 and i,j : 30. The KEL/TMOS molar ratio is fixed to 0.024 . 
Table 1 : Lattice parameter $(\mathrm{a})$, hydrophobic radius $\left(\mathrm{R}_{\mathrm{H}}\right)$ and cross-sectional area $(\mathrm{S})$ for the cubic and hexagonal phases at different surfactant/water ratios

\begin{tabular}{ccccc}
\hline $\begin{array}{c}\text { Composition } \\
\text { (surfactant/ water) }\end{array}$ & Phase & $\mathrm{a}(\mathrm{nm})$ & $\mathrm{R}_{\mathrm{H}}(\mathrm{nm})$ & $\mathrm{S}\left(\mathrm{nm}^{2}\right)$ \\
\hline 1.0 & $\mathrm{Pm} 3 \mathrm{n}$ & 20.0 & 3.5 & 1.2 \\
0.67 & $\mathrm{H}_{1}$ & 10.7 & 2.6 & 1.1 \\
0.54 & $\mathrm{H}_{1}$ & 10.4 & 2.6 & 1.1 \\
\hline
\end{tabular}


Table 2 : Mesoporous materials : cell parameter $\left(\mathrm{a}_{0}\right)$, specific surface area $\left(\mathrm{S}_{\mathrm{BET}}\right)$, pore volume $\left(\mathrm{V}_{\mathrm{p}}\right)$, pore diameter $(\varnothing)$ and pore wall thickness (e) concerning the samples obtained at different surfactant concentrations. The KEL/TMOS molar ratio is fixed to 0.024.

\begin{tabular}{cccccc}
\hline $\begin{array}{c}\text { KEL }] \\
(\mathrm{wt} \%)\end{array}$ & $\mathrm{a}_{0}(\mathrm{~nm})$ & $\mathrm{S}_{\mathrm{BET}}\left(\mathrm{m}^{2} / \mathrm{g}\right)$ & $\mathrm{V}_{\mathrm{p}}{ }^{*}\left(\mathrm{~cm}^{3} / \mathrm{g}-\right.$ & $\varnothing^{*}(\mathrm{~nm})$ & $\mathrm{e}(\mathrm{nm})$ \\
\hline 2.5 & 8.4 & 702 & 0.7 & 4.5 & 3.9 \\
5 & 9.0 & 872 & 0.6 & 5.4 & 6.6 \\
10 & 9.7 & 928 & 1.4 & 5.7 & 4.0 \\
20 & 11.5 & 885 & 1.5 & 7.1 & 4.4 \\
30 & - & 560 & 1.4 & 10.7 & - \\
40 & & 466 & 1.4 & 18.5 & \\
\hline
\end{tabular}

* Values obtained from BJH method applied to the adsorption branch of the isotherm

- Wormhole like structure 
Scheme 1

Hydrophilic 
Figure 1

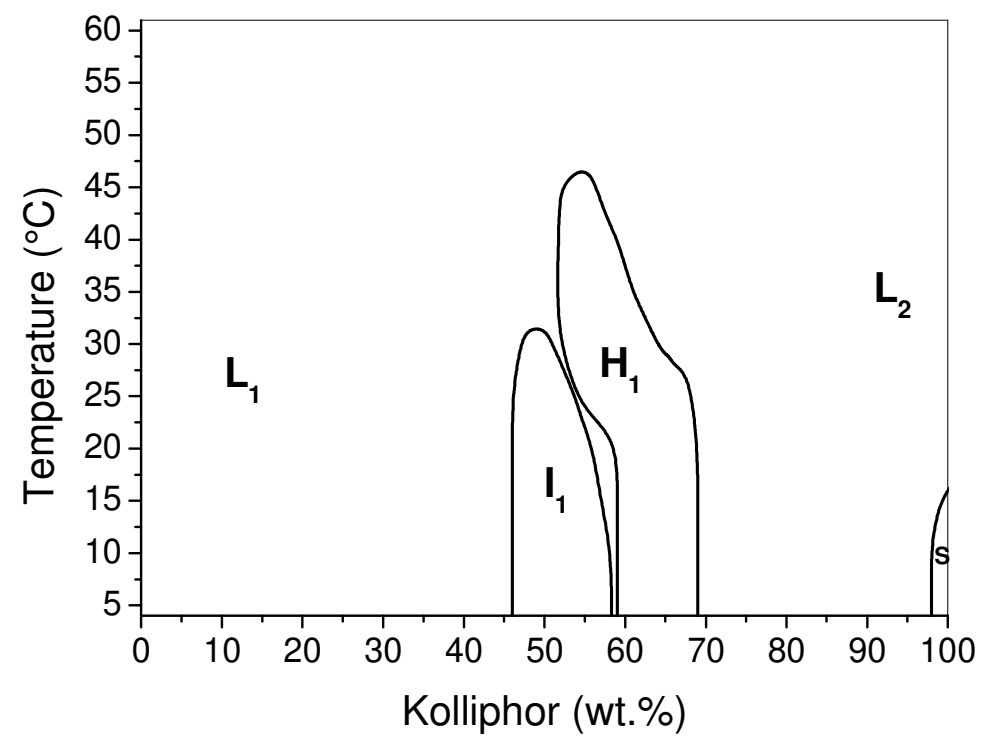


Figure 2
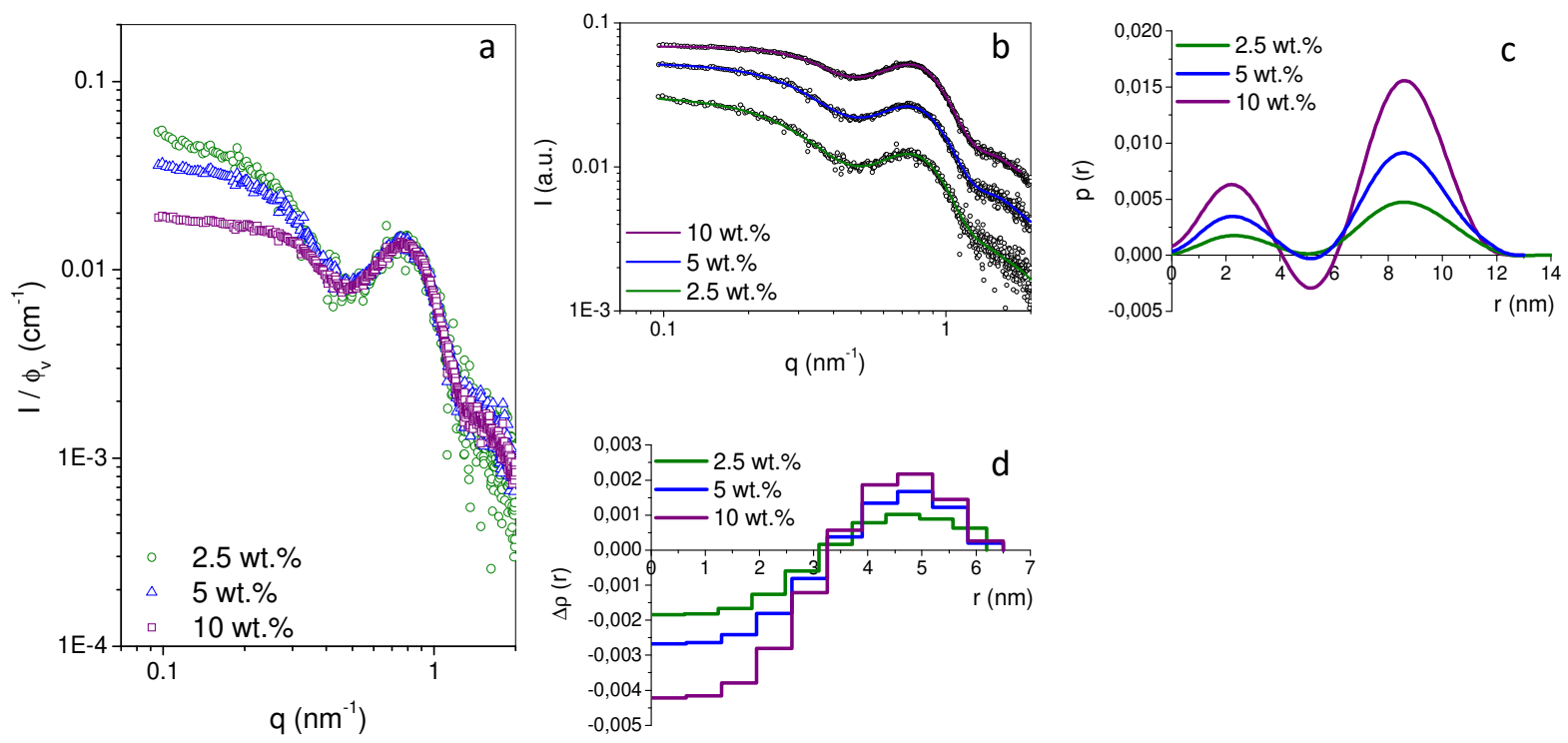
Figure 3
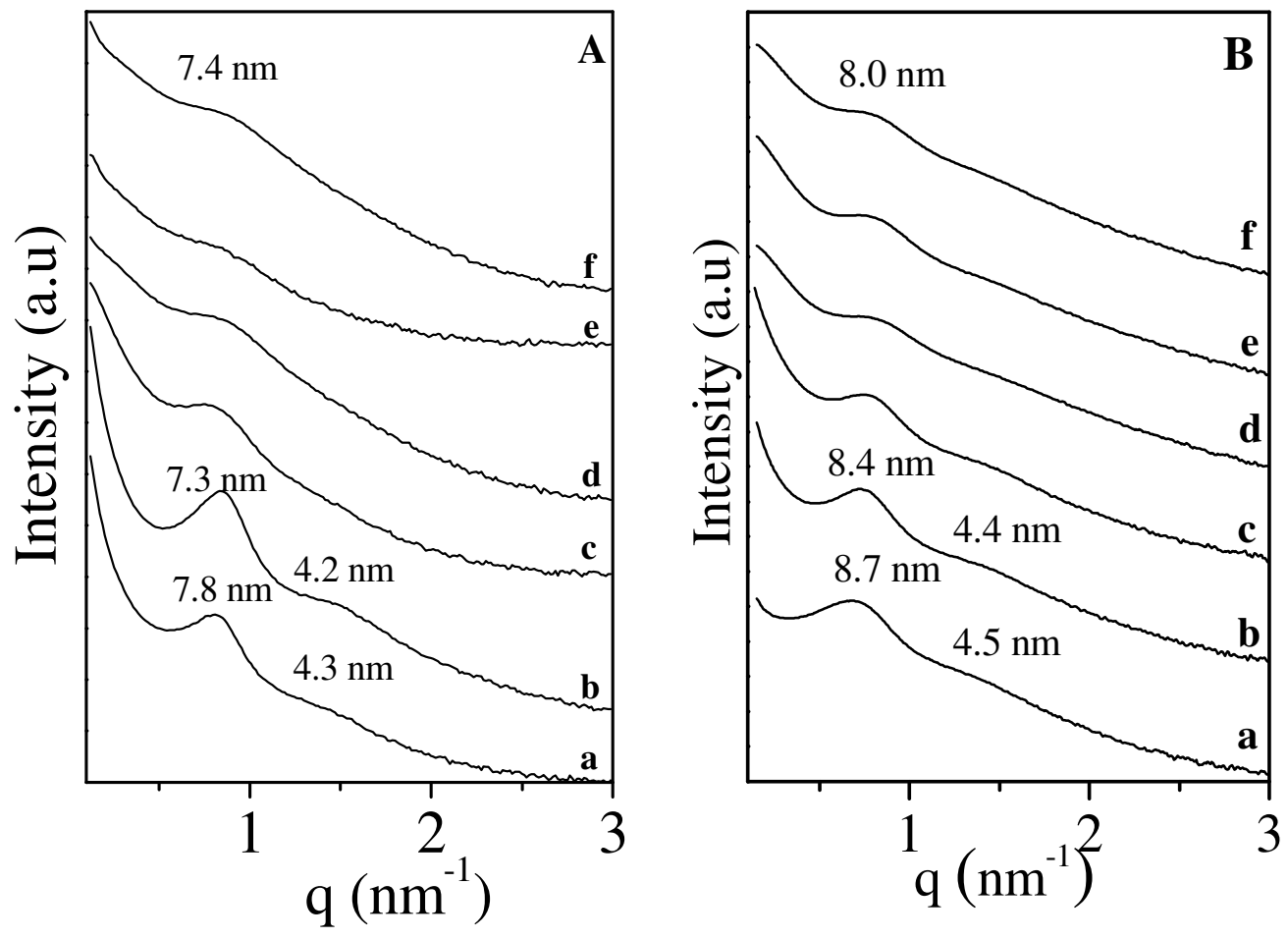


\section{Figure 4}

A

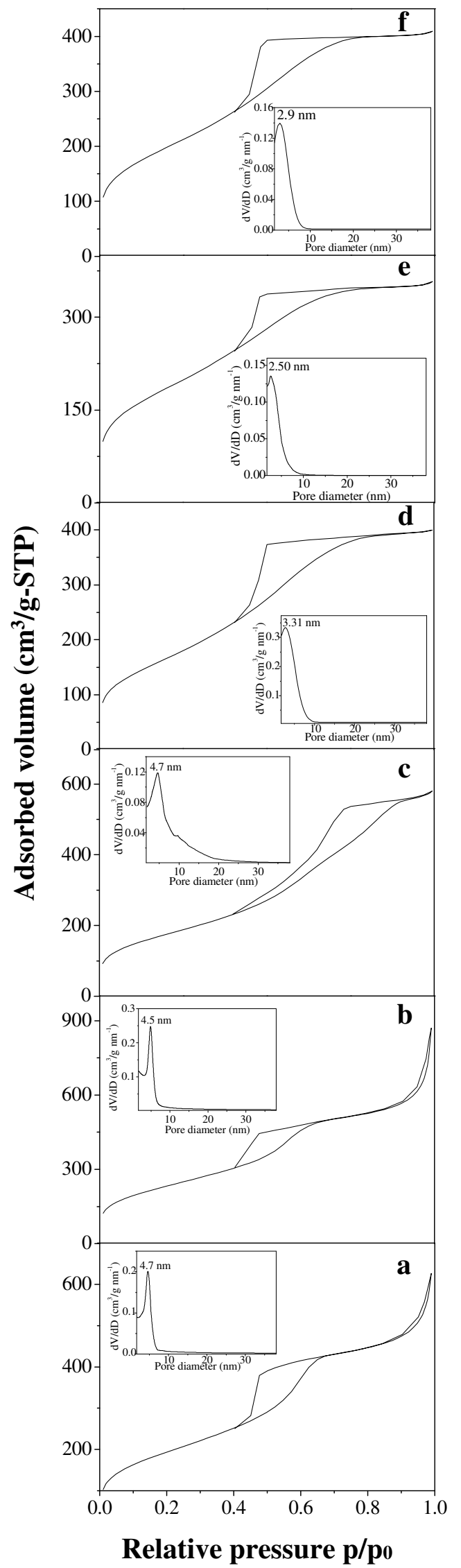

B

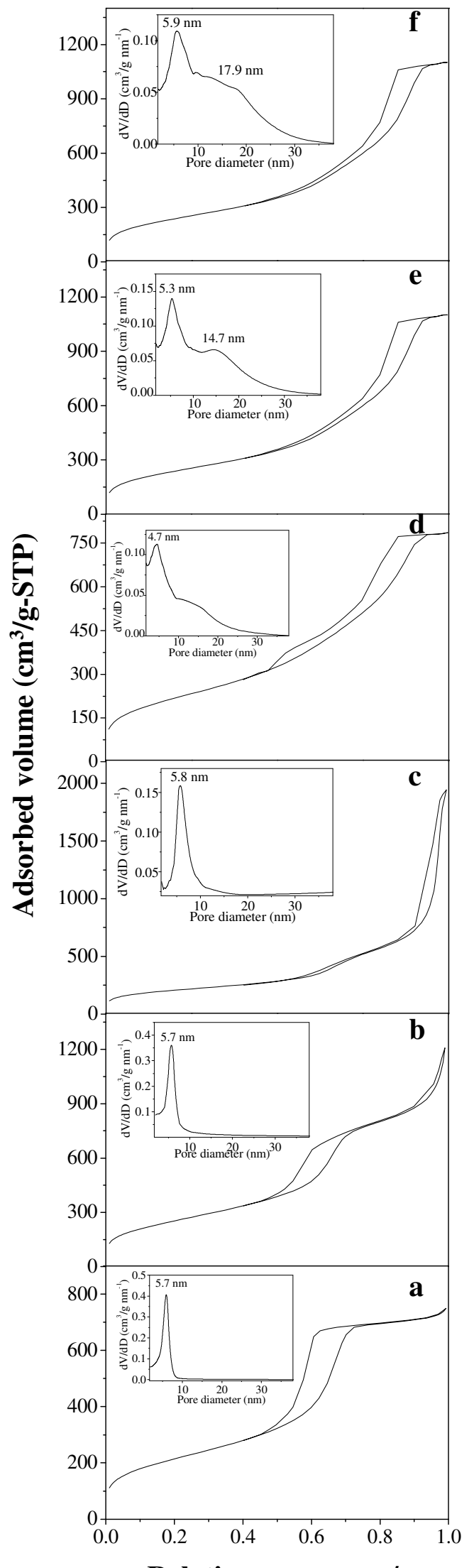

Relative pressure p/po 


\section{Figure 5}

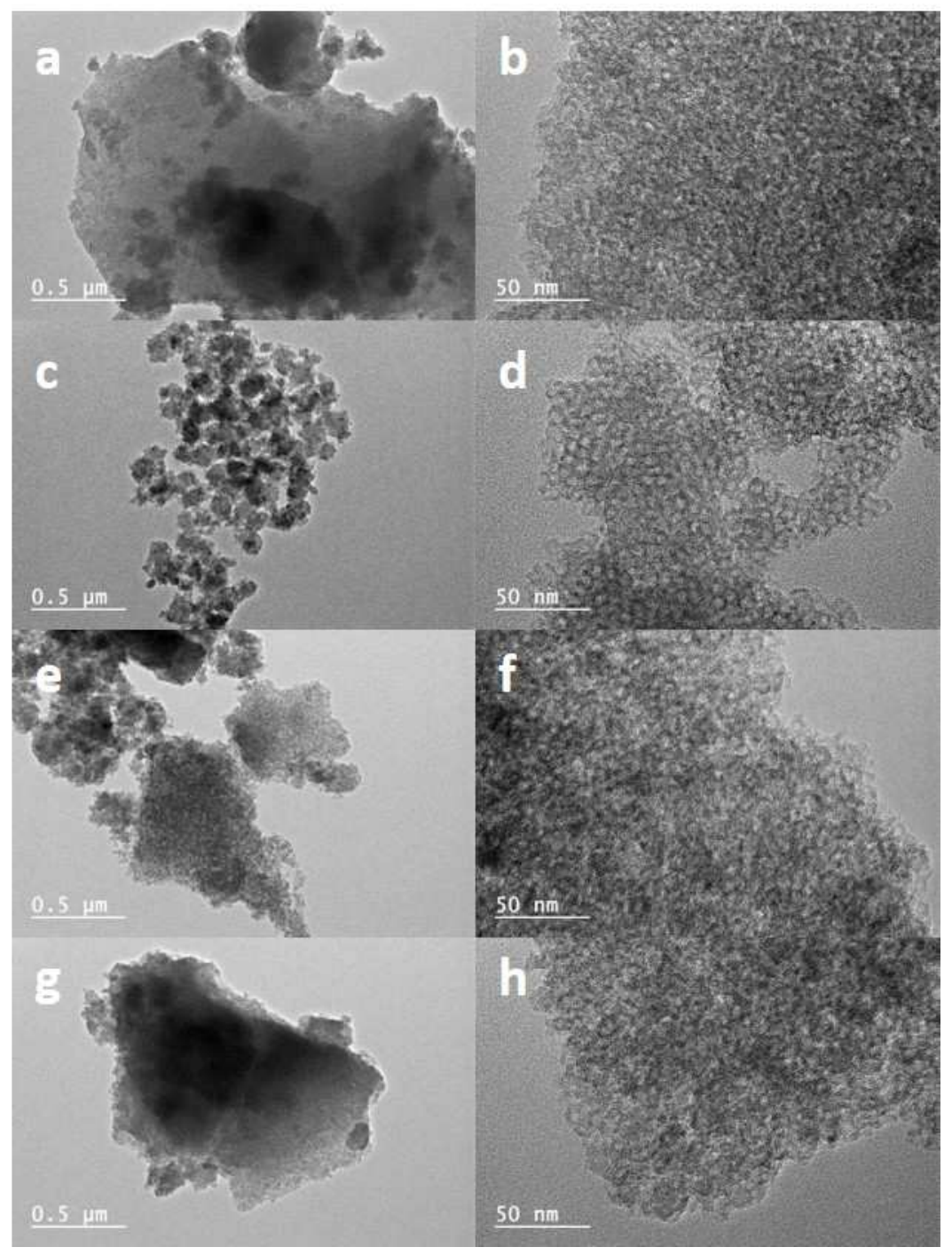


Figure 6
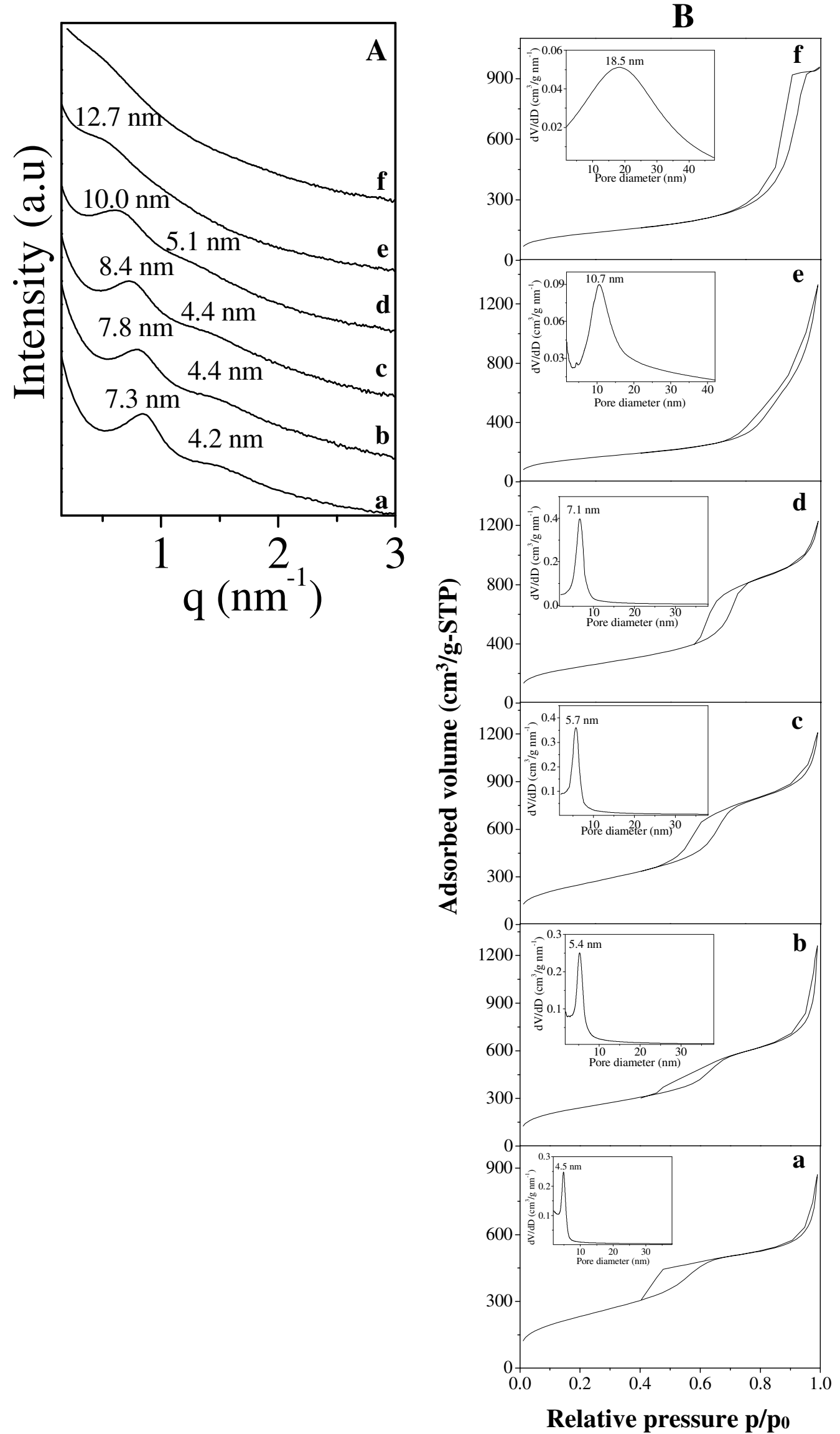


\section{Figure 7}

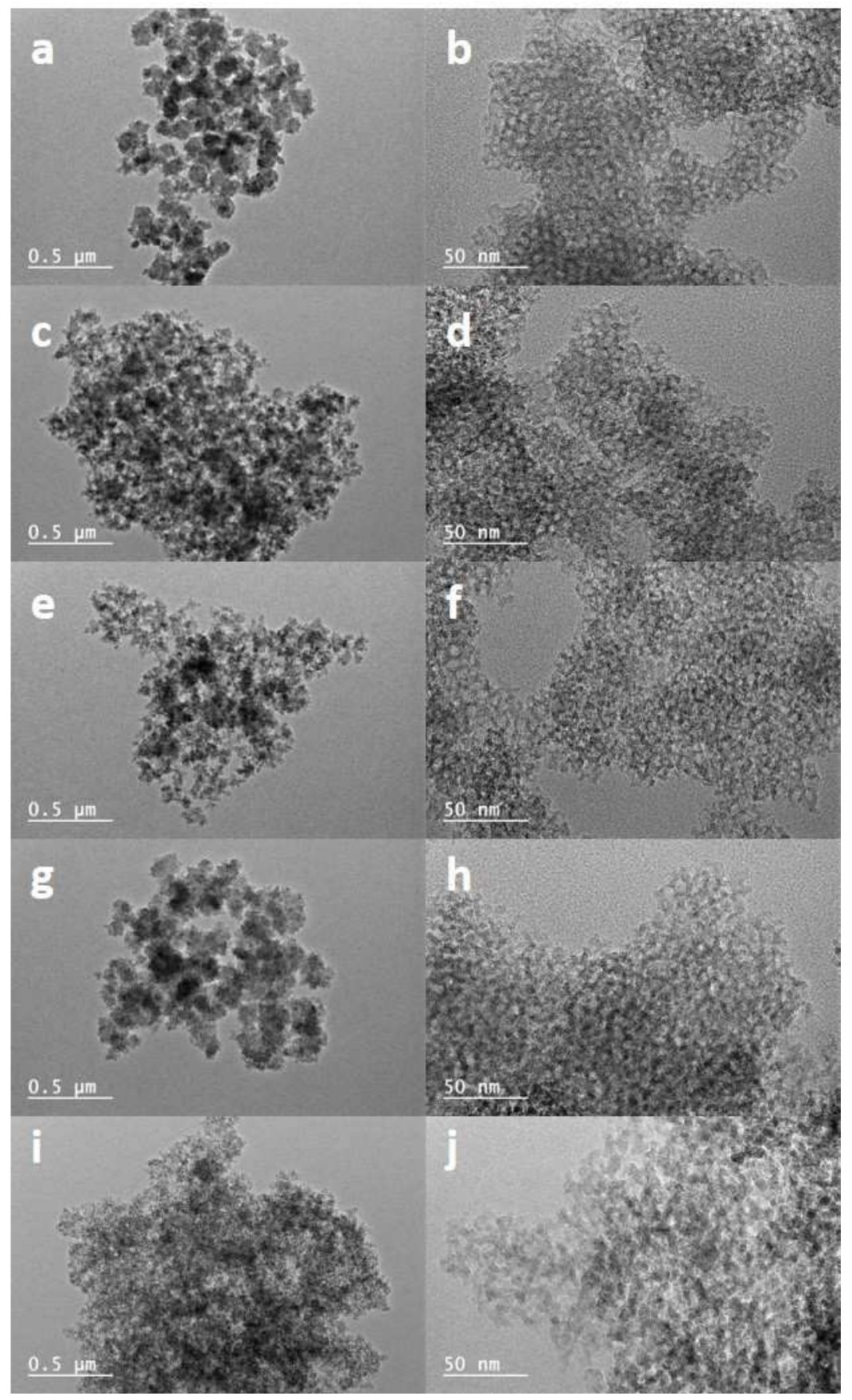




\section{Graphical abstract}

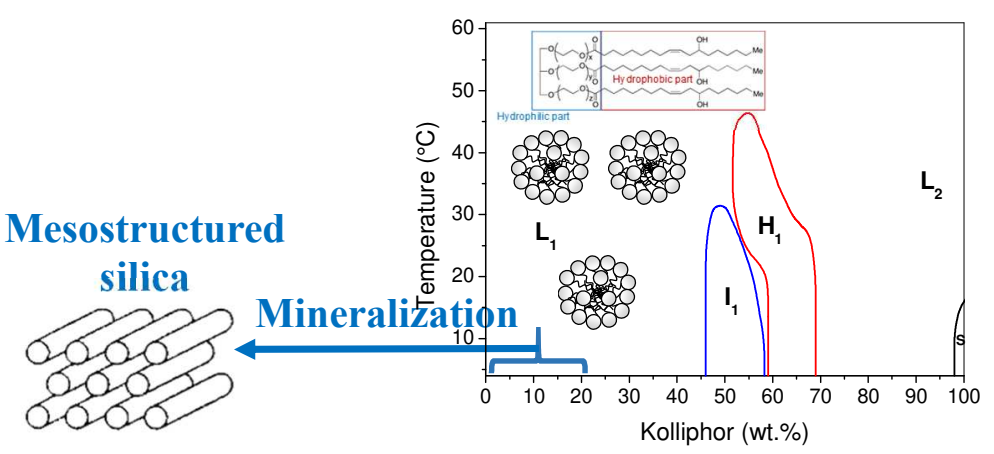

